\title{
Perfil dos ingressantes na licenciatura em educação física e suas experiências com as ginásticas competitivas ${ }^{1}$
}

\section{Physical education teaching students' profile and their experiences with competitve gymnastics}

\section{Perfil de los estudiantes de educación física y sus experiencias con la gimnasia de competición}

\author{
(iD) Bruna Sontag \\ Universidade Estadual de Maringá, Maringá, Paraná, Brasil \\ e-mail: sontagbruna@gmail.com \\ iD Verónica Gabriela Silva Piovani \\ Universidade Estadual do Oeste do Paraná, Marechal Cândido Rondon, Paraná, Brasil \\ e-mail: veronica.piovani@unioeste.br \\ (iD) Jorge Both \\ Universidade Estadual de Londrina, Londrina, Paraná, Brasil \\ e-mail: jorgeboth@uel.br \\ (iD) leda Parra Barbosa-Rinaldi \\ Universidade Estadual de Maringá, Maringá, Paraná, Brasil \\ e-mail: parrarinaldi@hotmail.com
}

Resumo: O objetivo foi analisar as características sociodemográficas dos estudantes ingressantes na Licenciatura em Educação Física (EF) frente às atividades de ginástica de competição desenvolvidas durante sua Educação Básica. Participaram 168 alunos ingressantes, no ano de 2017, em cursos de Licenciatura em EF de quatro universidades públicas do Paraná. Utilizou-se um questionário com informações sociodemográficas e questões fechadas. Para a análise utilizou-se a estatística descritiva

\footnotetext{
10 presente trabalho contou com o financiamento do Conselho Nacional de Desenvolvimento Científico e Tecnológico (CNPq) - Programa Institucional de Bolsas de Iniciação Científica (PIBIC).
} 
e indutiva. Observou-se que $81,5 \%$ dos alunos não tiveram ginástica de competição na EF escolar e 17,9\% tiveram a vivência fora da mesma. Conclui-se que a maioria dos alunos que teve ginástica de competição fora da escola pertencia à universidade 4 (U4), era do sexo feminino e estudou em escolas privadas.

Palavras chave: Formação profissional, Ginástica, Educação Física Licenciatura.

Abstract: The study analysed the sociodemographic characteristics of the entering students of the Physical Education Teaching Degree within the competitive gymnastics activities experienced during their Primary and Secondary Education. The samplewas 168 students of four public universities of Paraná state. A sociodemographic and closed ended questionnaire was used for data collection. Descriptive and inductive statistic was used for data analysis. The results showed that $81,5 \%$ of the students did not have competitive gymnastics during the Physical Education scholar lessons and $17.9 \%$ had the experience outside the school. Thus, the majority of the students who had competitive gymnastics outside school belonged to university 4, was female and studied in private schools.

Keywords: Professional Training, Gymnastics, Physical Education Teaching Degree.

Resumen: Se analizaron las características sociodemográficas de estudiantes que recién ingresaban a la Licenciatura en Educación Física (EF), considerando sus experiencias con la gimnasia de competición en su educación básica. Participaron 168 estudiantes de cursos de Licenciatura en EF de cuatro universidades públicas del estado de Paraná. Se usó un cuestionario sociodemográfico y preguntas cerradas. Para el análisis de datos se utilizó la estadística descriptiva e inductiva. Se verificó que 81,5\% de los estudiantes no tuvo gimnasia de competición en la EF escolar y que $17,9 \%$ tuvo la vivencia fuera de ésta. La mayoría de los estudiantes que tuvo gimnasia competitiva fuera de la escuela pertenecía a la universidad 4 , era del sexo femenino y estudiaba en escuelas privadas.

Palabras clave: Capacitación profesional, Gimnasia, Licenciatura en Educación Física.

Submetido em: 06-12-2019

Aceito em: 08-04-2020 
Perfil dos ingressantes na licenciatura em educação física e suas experiências... Bruna Sontag • Verónica Gabriela Silva Piovani • Jorge Both • leda Parra Barbosa-Rinaldi

\section{Introdução}

A escolha de uma profissão não é uma tarefa fácil, esta decisão é tomada desde muito antes do ingresso no ensino superior, a partir de experiências no decorrer da infância, adolescência e juventude e do contato com a formação básica. Esse processo de socialização, chamado de socialização profissional, é construído ao longo da vida do indivíduo e soma-se à influência de agentes exteriores (família, escola etc.) que transmitem valores, normas e regras, desenvolvendo a capacidade do indivíduo de interpretar e reinterpretar o mundo por si mesmo (GOMES; QUEIRÓS; BATISTA, 2014).

Nesse sentido, Lawson (1983) diferenciou três tipos de socialização que deveriam ser observadas para melhor compreender a socialização profissional de docentes de educação física (EF): aculturação (ou socialização antecipatória, que se inicia desde o nascimento, compreende os significados adquiridos pelo contato com distintos agentes sociais, como a família, escola, amigos etc.), socialização profissional (ou formação inicial, que é o processo no qual os professores adquirem ou mantêm conhecimento, valores e habilidades necessárias ao ensino da EF) e socialização organizacional (ou socialização ao longo da carreira, que ocorre quando os professores, já inseridos na profissão, adquirem ideais e conhecimentos que são valorizados pela organização a qual pertencem).

Assim, ao entrar em um curso de formação profissional para docência, o futuro profissional traz consigo um repertório de aprendizado adquirido por meio de observações de professores, e possui concepções sobre o que é ser professor a partir das experiências pessoais vividas no papel de aluno (GRAÇA, 2014). Esse processo de socialização antecipatória, que ocorre a partir das trocas constantes entre indivíduo e sociedade, promove aprendizagens e experiências que capacitam as pessoas para a vida ativa, sendo, assim, primordial para a concepção da profissão (BARROS, 2011). 
Perfil dos ingressantes na licenciatura em educação física e suas experiências...

Bruna Sontag • Verónica Gabriela Silva Piovani • Jorge Both • leda Parra Barbosa-Rinaldi

Por outro lado, o papel da formação inicial é, geralmente, o que tem uma incidência menor na socialização profissional docente, comparada à socialização antecipatória e à socialização ao longo da carreira. Na área da Educação Física (EF), Onofre e Carvalho (2004) e Onofre e Martins (2014) apontam que as crenças sobre educação que os alunos formaram durante sua socialização antecipatória, e que muitas vezes são desfavoráveis, não sofrem alterações no percurso da graduação.

Ao se tratar, especificamente, das experiências anteriores à graduação em EF, observa-se que a vivência, ou não, do conteúdo ginástica no percurso escolar pode incidir no desenvolvimento da aprendizagem dos estudantes durante o curso de graduação e sua futura intervenção profissional. De fato, Barbosa-Rinaldi e Souza (2003) afirmaram que o conhecimento prévio que o acadêmico de EF adquire, ao longo de sua formação inicial sobre ginástica, soma-se às reflexões e conteúdos trabalhados durante o processo de formação profissional. E, ainda acrescentaram que os estudantes, ao chegarem às universidades, trazem consigo a construção histórica de suas vidas nas escolas e essa bagagem, provavelmente, interfere na sua escolha profissional e na sua futura formação profissional.

No entanto, Barbosa-Rinaldi e Souza (2003) citam que existe um círculo vicioso de desconhecimento da ginástica: o aluno não desfruta do conteúdo gímnico na escola e quando se torna profissional da área de EF reproduz esta conduta de negligência. Esta negligência pode ter várias causas, como: a falta de competência por parte do curso de graduação em preparar os futuros profissionais, aliada à falta de experiência já existente, ou até mesmo a falta de materiais e espaço adequados para a realização da prática (COSTA et al., 2016). Porém, a principal causa da ausência do conteúdo é a falta de preparo adequado do profissional da área (BARBOSA-RINALDI; SOUZA, 2003).

A presença da ginástica na vida escolar colabora com a formação em EF, pois, por meio de elementos próprios da modalidade, como elementos acrobáticos, elementos corporais e manejos de 
Perfil dos ingressantes na licenciatura em educação física e suas experiências... Bruna Sontag • Verónica Gabriela Silva Piovani • Jorge Both • leda Parra Barbosa-Rinaldi

aparelhos, constrói-se o repertório motor do aluno, que o prepara e enriquece para sua futura prática profissional (SOUZA, 1997).

Entre as diversas modalidades gímnicas, as competitivas (ginástica rítmica, ginástica artística, ginástica aeróbica, roda acrobática, trampolim acrobático, tumbling) se legitimam como práticas ricas e positivas para o contexto escolar, pois oferecem aos alunos a possibilidade de exploração motora, espacial, criativa, cognitiva, afetiva e social, além de proporcionarem momentos de alegria e prazer (MERIDA; NISTA-PICCOLO; MERIDA, 2008; ANDRADE, et al. 2016). Por estes motivos, é um conteúdo de ensino que aparece tanto nos Parâmetros Curriculares Nacionais (PCN) (BRASIL, 1997) como na Base Nacional Comum Curricular (BNCC) (BRASIL, 2017).

Ao considerar que a aprendizagem das ginásticas de competição, dentro e fora da educação básica, influencia as crenças e as aprendizagens a serem desenvolvidas durante a formação inicial em EF, o objetivo deste estudo foi analisar as características sociodemográficas de estudantes ingressantes em universidades públicas do estado do Paraná no curso de Licenciatura em Educação Física, frente às atividades de ginástica de competição desenvolvidas durante a Educação Básica.

\section{Métodos}

Realizou-se uma pesquisa descritiva com abordagem quantitativa dos dados (CERVO; BERVIAN, 1996). A amostra foi composta por 168 estudantes do curso de Licenciatura em Educação Física de quatro universidades públicas do Estado do Paraná (descritas como: U1, U2, U3 e U4), matriculados no ano letivo de 2017. As universidades estavam localizadas nas regiões noroeste e oeste do Estado do Paraná, em cidades com populações entre 52 mil e 485 mil habitantes, aproximadamente.

Para a coleta de dados foi utilizado um questionário com informações sociodemográficas e questões fechadas sobre o ensino 
Perfil dos ingressantes na licenciatura em educação física e suas experiências...

Bruna Sontag • Verónica Gabriela Silva Piovani • Jorge Both • leda Parra Barbosa-Rinaldi

do conteúdo ginásticas de competição no Ensino Fundamental e Médio. O questionário, construído para fins desta pesquisa, passou por uma avaliação de conteúdo e clareza da linguagem por parte de três professores de Educação Física, especialistas na área de ginástica. A avaliação do conteúdo consistiu na análise das questões que seriam aplicadas, considerando se elas estavam relacionadas ao objetivo e ao tema do estudo.

Além disso, foi avaliada a adequação, a coerência da linguagem e a organização das perguntas. Em cada pergunta, os especialistas deveriam indicar se a questão era: Não válida; Pouco Válida ou Válida, assim como poderiam indicar sugestões ou comentários para a construção do instrumento (SANTOS; GHELLER, 2012). Foram propostas 19 questões (11 perguntas sociodemográficas e oito questões fechadas sobre a experiência de ginástica de competição durante a Educação Básica). Para uma questão ser eliminada, deveria ser indicada como inválida por dois ou três especialistas e outras questões poderiam ser acrescentadas por qualquer um dos especialistas. Desta maneira, o questionário foi adequado, seguindo as sugestões dos professores especialistas na área, sendo que não foi eliminada nem acrescentada nenhuma questão ao instrumento proposto. Somente foram realizadas adequações na escrita sugeridas pelos especialistas.

Para analisar as informações sociodemográficas e as respostas das questões fechadas foram utilizadas as análises estatísticas descritivas e indutivas. Para verificar a normalidade dos dados, foi utilizado o teste de Komolgorov-Smirnov, o qual constatou que não existia distribuição normal dos dados. Sendo assim, foi utilizada a estatística não paramétrica, que foi representada pela mediana (Md) como medida de tendência central, e o intervalo interquartil (Q1-Q3) como medida de dispersão.

Para verificar as associações entre as variáveis, foram aplicados os testes Prova U de Mann Whitney, para comparar dois grupos independentes, e o teste Kruskal Wallis, para comparar três ou mais grupos independentes. Também foram utilizados o teste Quiquadradro de Pearson e o teste Exato de Fisher. Todas as análises 
Perfil dos ingressantes na licenciatura em educação física e suas experiências... Bruna Sontag • Verónica Gabriela Silva Piovani • Jorge Both • leda Parra Barbosa-Rinaldi

adotaram um valor de significância maior ou igual a 95\% $(p<0,05)$ e foram realizadas no programa estatístico SPSS, versão 20.0.

Por fim, destaca-se que o presente estudo obteve a aprovação do Comitê Permanente de Ética em Pesquisas com Seres Humanos da Universidade Estadual de Maringá, sob o parecer n 2.410.354.

\section{Resultados}

Ao realizar a análise das informações do questionário sociodemográfico foi possível estabelecer o perfil dos estudantes pesquisados, conforme é apresentado na Tabela 1.

Tabela 1. Distribuição de frequência de variáveis sociodemográficas e a experiência de ginástica competitiva dentro e fora da escola.

\begin{tabular}{|c|c|c|}
\hline Variável & Categoria & Frequência \\
\hline \multirow{4}{*}{ Universidade } & 1 & $50(29,8)$ \\
\hline & 2 & $47(28,0)$ \\
\hline & 3 & $39(23,2)$ \\
\hline & 4 & $32(19,0)$ \\
\hline \multirow[b]{2}{*}{ Faixa etária } & 18 anos & $95(56,5 \%)$ \\
\hline & $\begin{array}{c}19 \text { anos ou } \\
\text { mais }\end{array}$ & $73(43,5 \%)$ \\
\hline \multirow{2}{*}{ Sexo } & Feminino & $84(50 \%)$ \\
\hline & Masculino & $84(50 \%)$ \\
\hline \multirow{3}{*}{ Estado civil } & Solteiro & $157(93,5 \%)$ \\
\hline & Casado & $9(5,4 \%)$ \\
\hline & Outro & $2(1,2 \%)$ \\
\hline \multirow{2}{*}{ Tipo de escola $1^{\circ}$ a $5^{\circ}$ ano } & Pública & $133(79,2 \%)$ \\
\hline & Privada & $29(17.3 \%)$ \\
\hline \multirow{2}{*}{ Tipo de escola $6^{\circ}$ a $9^{\circ}$ ano } & Pública & $138(82,2 \%)$ \\
\hline & Privada & $30(17,9 \%)$ \\
\hline \multirow{2}{*}{ Tipo de escola Ensino Médio $1^{\circ}$ ano } & Pública & $133(79,2 \%)$ \\
\hline & Privada & $35(20,8 \%)$ \\
\hline \multirow{2}{*}{ Tipo de escola Ensino Médio $2^{\circ}$ ano } & Pública & $131(78,0 \%)$ \\
\hline & Privada & $37(22,0 \%)$ \\
\hline
\end{tabular}


Perfil dos ingressantes na licenciatura em educação física e suas experiências...

\begin{tabular}{ccc}
\hline Tipo de escola Ensino Médio $3^{\circ}$ ano & Pública & $130(77,4 \%)$ \\
& Privada & $38(22,6 \%)$ \\
\hline \multirow{2}{*}{ Ano de conclusão } & Até 2015 & $71(42,4 \%)$ \\
& 2016 & $97(57,6)$ \\
\hline \multirow{2}{*}{ Outra graduação } & Sim & $16(9,5 \%)$ \\
& Não & $152(90,5)$ \\
\hline \multirow{2}{*}{ Possui ocupação remunerada } & Sim & $54(32,1 \%)$ \\
& Não & $114(67,9 \%)$ \\
\hline \multirow{2}{*}{ Turno do curso } & Matutino & $57(33,9 \%)$ \\
& Noturno & $45(26,8 \%)$ \\
Teve ginástica de competição na EF escolar & Integral & $66(39,3 \%)$ \\
\hline \multirow{2}{*}{ Teve ginástica de competição fora da EF } & Sim & $31(18,5 \%)$ \\
escolar & Não & $137(81,5 \%)$ \\
\hline
\end{tabular}

De acordo com os resultados apresentados pela Tabela 1, do total de alunos pesquisados nas quatro universidades públicas do estado do Paraná, 29,8\% alunos pertenciam à U1, 28\% à U2, 23,2\% alunos à U3 e $19 \%$ à U4. A respeito do turno do curso, 39,3\% cursavam em período integral, $33,9 \%$ em período matutino e $26,8 \%$ em período noturno.

Em relação à idade, 56,5\% dos participantes tinham 18 anos e os demais (43,5\%) tinham 19 anos ou mais. O sexo apresentou distribuição proporcional, sendo 84 mulheres e 84 homens. Quanto ao estado civil, os participantes eram, na sua maioria, solteiros (93,5\%), 5,4\% casados e 1,2\% em outra situação.

Para descrever o tipo de instituição na qual realizaram o Ensino fundamental, optou-se por dividir os anos da seguinte forma: $1^{\circ}$ ao $5^{\circ}$ ano e $6^{\circ}$ ao $9^{\circ}$ ano. Assim, observou-se que a maioria dos estudantes cursou em instituições públicas ambos os níveis de ensino (82,7\% e $82,2 \%$, respectivamente). O Ensino Médio foi individualizado por ano, sendo que também os três anos de Ensino Médio foram cursados majoritariamente em instituições públicas $\left(1^{\circ}\right.$ ano: $79,2 \%, 2^{\circ}$ ano: $78 \%$ e $3^{\circ}$ ano: $77,4 \%$ ). Além disso, ressalta-se que a maioria dos estudantes concluiu o Ensino Médio no ano de 2016 
Perfil dos ingressantes na licenciatura em educação física e suas experiências... Bruna Sontag • Verónica Gabriela Silva Piovani • Jorge Both • leda Parra Barbosa-Rinaldi

$(57,1 \%)$, sendo que o restante concluiu seus estudos no ano de 2015 (18,5\%) e em 2014 (8,3\%).

Quando perguntados se possuíam outra graduação, 90,5\% dos alunos responderam que não tinham, enquanto 9,5\% declararam ter outra graduação. Em relação a possuir ocupação remunerada, evidenciou-se que grande parte dos estudantes não tinha $(67,9 \%)$ e 32,1\% tinham ocupação remunerada.

Em relação à vivência da ginástica de competição na EF escolar, 81,5\% dos alunos responderam que não tiveram esta vivência, enquanto apenas $18,5 \%$ responderam afirmativamente a questão. Por fim, observou-se que somente $17,9 \%$ tiveram a vivência de ginástica de competição fora da EF escolar.

Ao realizar a associação entre a avaliação que os alunos faziam sobre a abordagem metodológica do conteúdo ginástica de competição na EF escolar e o perfil dos alunos, observou-se que a universidade a qual pertenciam, a faixa etária, o sexo, o tipo de escola no Ensino Fundamental e Médio, o ano de conclusão do Ensino Médio, a realização de outra graduação, o turno do curso de EF e se tiveram ginástica de competição fora do ambiente escolar, não apresentaram associação significativa (Tabela 2). 
Perfil dos ingressantes na licenciatura em educação física e suas experiências... Bruna Sontag • Verónica Gabriela Silva Piovani • Jorge Both • leda Parra Barbosa-Rinaldi

\section{Tabela 2. Associação entre a avaliação da abordagem metodológica do conteúdo ginástica de competição na EF escolar e o perfil dos estudantes pesquisados.}

\begin{tabular}{|c|c|c|c|}
\hline Variáveis & Categorias & Md(Q1-Q3) & $\mathbf{P}$ \\
\hline \multirow{4}{*}{ Universidade } & U1 & $1,5(1,0-2,0)$ & \multirow{4}{*}{$0,401 *$} \\
\hline & U2 & $2,0(1,0-2,0)$ & \\
\hline & U3 & $1,0(1,0-2,0)$ & \\
\hline & U4 & $2,0(1,0-2,0)$ & \\
\hline \multirow[b]{2}{*}{ Faixa etária } & Até 18 anos & $2,0(1,0-2,0)$ & \multirow[b]{2}{*}{$0,909 * *$} \\
\hline & $\begin{array}{c}19 \text { anos ou } \\
\text { mais }\end{array}$ & $2,0(1,0-2,0)$ & \\
\hline \multirow{2}{*}{ Sexo } & Feminino & $2,0(1,0-2,0)$ & \multirow{2}{*}{0,590 ** } \\
\hline & Masculino & $2,0(1,0-2,0)$ & \\
\hline Tipo de escola & Pública & $2,0(1,0-2,0)$ & \multirow{2}{*}{$0,090 * *$} \\
\hline $1^{\circ}$ ao $5^{\circ}$ ano & Privada & $2,0(1,0-2,0)$ & \\
\hline \multirow{2}{*}{ Tipo de escola do $6^{\circ}$ ao $9^{\circ}$ ano } & Pública & $2,0(1,0-2,0)$ & \multirow{2}{*}{$0,342 * \star$} \\
\hline & Privada & $2,0(1,0-2,0)$ & \\
\hline \multirow{2}{*}{ Tipo de escola Ensino Médio 1} & Pública & $2,0(1,0-2,0)$ & \multirow{2}{*}{$0,513 * *$} \\
\hline & Privada & $2,0(1,0-2,0)$ & \\
\hline \multirow{2}{*}{ Tipo de escola Ensino Médio 2} & Pública & $2,0(1,0-2,0)$ & \multirow{2}{*}{$0,464 * *$} \\
\hline & Privada & $2,0(1,0-2,0)$ & \\
\hline \multirow{2}{*}{ Tipo de escola Ensino Médio 3} & Pública & $2,0(1,0-2,0)$ & \multirow{2}{*}{$0,407 * *$} \\
\hline & Privada & $2,0(1,0-2,0)$ & \\
\hline \multirow{2}{*}{ Ano de conclusão Ensino Médio } & Até 2015 & $2,0(1,0-2,0)$ & \multirow{2}{*}{$0,807 * *$} \\
\hline & 2016 & $2,0(1,0-2,0)$ & \\
\hline \multirow{2}{*}{ Outra graduação } & $\operatorname{Sim}$ & $2,0(1,0-2,0)$ & \multirow{2}{*}{$0,925^{* *}$} \\
\hline & Não & $2,0(1,0-2,0)$ & \\
\hline \multirow{2}{*}{ Possui ocupação remunerada } & Sim & $2,0(1,0-2,0)$ & \multirow{2}{*}{$0,035 * *$} \\
\hline & Não & $1,0(1,0-2,0)$ & \\
\hline \multirow{3}{*}{ Turno do curso } & Matutino & $2,0(1,0-2,0)$ & \multirow{3}{*}{$0,338 *$} \\
\hline & Noturno & $1,0(1,0-2,0)$ & \\
\hline & Integral & $1,0(1,0-2,0)$ & \\
\hline \multirow{2}{*}{$\begin{array}{l}\text { Teve ginástica de competição na EF } \\
\text { escolar }\end{array}$} & Sim & $3,0(2,0-3,0)$ & \multirow{2}{*}{$<0,001 * *$} \\
\hline & Não & $1,0(1,0-2,0)$ & \\
\hline \multirow{2}{*}{$\begin{array}{l}\text { Teve ginástica de competição além da } \\
\text { escola }\end{array}$} & Sim & $2,0(1,0-2,25)$ & \multirow{2}{*}{$0,309 * *$} \\
\hline & Não & $2,0(1,0-2,0)$ & \\
\hline
\end{tabular}

* Probabilidade estimada pelo teste Kruskal Wallis.

** Probabilidade estimada pelo teste Prova U de Man-Whitney. 
Perfil dos ingressantes na licenciatura em educação física e suas experiências... Bruna Sontag • Verónica Gabriela Silva Piovani • Jorge Both • leda Parra Barbosa-Rinaldi

Observa-se, na Tabela 2, que as variáveis: possui ocupação remunerada e tiveram ginástica de competição na EF escolar apresentaram associação significativa. Neste caso, observou-se que o perfil dos estudantes que perceberam a abordagem do ensino da ginástica de competição de forma mais positiva foram aqueles que tinham ocupação remunerada $(p=0,035)$ e tiveram ginástica de competição na EF escolar $(p<0,001)$.

Ao relacionar a experiência com ginástica de competição fora da EF escolar com o perfil dos participantes do estudo, evidenciou-se que as variáveis: faixa etária, tipo de escola do $1^{\circ}$ ao $5^{\circ}$ ano e do $6^{\circ}$ ao $9^{\circ}$ ano, possui outra graduação, possui ocupação remunerada e, turno do curso não apresentaram associação significativa $(p>0,05)$. Contudo, as variáveis: universidade $(p=0,003)$, sexo $(p=0,016)$, tipo de escola durante os três anos do Ensino Médio $(p<0,001)$ e se teve ginástica competitiva na EF escolar $(p=0,020)$ evidenciaram associação significativa (Tabela 3).

Tabela 3. Associação entre o perfil dos alunos e sua experiência com a ginástica de competição fora da escola.

\begin{tabular}{cccc}
\hline Variáveis Sociodemográficas & \multicolumn{2}{c}{$\begin{array}{c}\text { Ginástica fora da } \\
\text { escola }\end{array}$} & \multirow{2}{*}{$\mathbf{P}$} \\
\cline { 2 - 3 } Sim & Não & \\
n (\%) & $\mathbf{n}(\%)$ & \\
\hline Universidade & $7(14,0)$ & $43(86,0)$ & \\
U1 & $5(10,6)$ & $42(89,4)$ & \multirow{0}{*}{,003* } \\
U2 & $5(12,8)$ & $34(87,2)$ & \\
U3 & $13(40,6)$ & $19(59,4)$ & \\
U4 & & & \\
\hline Sexo & $21(25,0)$ & $63(75,0)$ & $\mathbf{0 , 0 1 6 *}$ \\
Feminino & $9(10,7)$ & $75(89,3)$ & \\
Masculino & & & \\
\hline Faixa etária & $19(20,0)$ & $76(80,0)$ & $0,408^{*}$ \\
Até 18 anos & $11(15,1)$ & $62(84,9)$ & \\
\hline 19 anos ou mais & &
\end{tabular}


Perfil dos ingressantes na licenciatura em educação física e suas experiências... Bruna Sontag • Verónica Gabriela Silva Piovani • Jorge Both • leda Parra Barbosa-Rinaldi

\begin{tabular}{|c|c|c|c|c|}
\hline \multicolumn{5}{|c|}{ Ensino Fundamental $1^{\circ}$ ao $5^{\circ}$ ano } \\
\hline Público & & $22(15,8)$ & $117(84,2)$ & $0,133^{*}$ \\
\hline Privado & & $8(27,6)$ & $21(72,4)$ & \\
\hline \multicolumn{5}{|c|}{ Ensino fundamental $6^{\circ}$ ao $9^{\circ}$ ano } \\
\hline Público & & $21(15,2)$ & $117(84,8)$ & $0,055^{*}$ \\
\hline Privado & & $9(30,0)$ & $21(70,0)$ & \\
\hline \multicolumn{5}{|c|}{ Ensino Médio $1^{\circ}$ ano } \\
\hline Público & & $15(11,3)$ & $118(88,7)$ & $<0,001 *$ \\
\hline Privado & & $15(42,9)$ & $20(57,1)$ & \\
\hline \multicolumn{5}{|c|}{ Ensino Médio $2^{\circ}$ ano } \\
\hline Público & & $16(12,2)$ & $114(87,7)$ & $<0,001 *$ \\
\hline Privado & & $14(36,8)$ & $24(63,2)$ & \\
\hline \multicolumn{5}{|c|}{ Ensino Médio $3^{\circ}$ ano } \\
\hline Público & & $16(12,3)$ & $114(87,7)$ & $<0,001 *$ \\
\hline Privado & & $14(36,8)$ & $24(63,2)$ & \\
\hline \multicolumn{5}{|c|}{ Ano de conclusão Ensino Médio } \\
\hline Até 2015 & & $13(18,3)$ & $58(81,7)$ & $0,896 *$ \\
\hline 2016 & & $17(17,5)$ & $80(82,5)$ & \\
\hline \multicolumn{5}{|c|}{ Possui outra graduação } \\
\hline Sim & & $5(31,2)$ & $11(68,8)$ & $0,131 * *$ \\
\hline Não & & $25(16,4)$ & $127(83,6)$ & \\
\hline \multicolumn{5}{|c|}{ Trabalha ou faz estágio não obrigatório } \\
\hline $\operatorname{Sim}$ & & $13(24,1)$ & $41(75,9)$ & $0,148 *$ \\
\hline Não & & $17(14,9)$ & $97(85,1)$ & \\
\hline \multicolumn{5}{|c|}{ Turno do curso de EF Licenciatura } \\
\hline Matutino & $14(24,6)$ & & $43(75,4)$ & $0199 *$ \\
\hline Noturno & $8(17,8)$ & & $37(82,2)$ & 0,195 \\
\hline Integral & $8(12,1)$ & & $58(87,9)$ & \\
\hline \multicolumn{5}{|c|}{ Teve ginástica competitiva na EF escolar } \\
\hline Sim & $10(32,3)$ & & $21(67,7)$ & $0,020 *$ \\
\hline Não & $20(14,6)$ & & $117(85,4)$ & \\
\hline
\end{tabular}

De acordo com a Tabela 3, evidenciou-se que o perfil dos estudantes que tiveram ginástica de competição fora da EF escolar correspondia ao dos estudantes da U4. Eram estudantes do sexo feminino, cursaram os três anos do Ensino Médio em instituições privadas e tiveram ginástica de competição na EF escolar. 
Perfil dos ingressantes na licenciatura em educação física e suas experiências... Bruna Sontag • Verónica Gabriela Silva Piovani • Jorge Both • leda Parra Barbosa-Rinaldi

Por outro lado, o perfil dos estudantes que não tiveram ginástica de competição fora da EF escolar correspondia ao dos estudantes das U1, U2 e U3. Eram estudantes do sexo masculino, realizaram os três anos do Ensino Médio em instituições públicas e não tiveram ginástica de competição na EF escolar.

\section{Discussão}

Verificou-se que a ginástica de competição, apesar de estar presente nos PCN da EF (ginástica olímpica e rítmica desportiva) (BRASIL, 1997) e na BNCC (BRASIL, 2017) como conteúdo da EF escolar, ainda é ausente nas aulas de EF nas instituições de ensino básico e médio, sendo vivenciada por $18,5 \%$ dos estudantes que participaram da pesquisa. Barbosa-Rinaldi e Souza (2003) observaram situação similar em um estudo realizado com 196 alunos ingressantes no curso de Licenciatura em EF das Universidades Estadual de Maringá e Estadual de Campinas, no ano de 2001.

No entanto, diversos autores apontaram a importância da aprendizagem das distintas modalidades de ginástica de competição na EF escolar para a formação de indivíduos críticos e autênticos (COSTA, et al. 2016; ANDRADE, et al. 2016). Nesse sentido, Oliveira e Porpino (2010) descrevem que a ginástica rítmica, no ambiente escolar, pode estimular a criatividade e a capacidade de resolução de problemas ao enfrentar novas possibilidades de movimentos. Ainda, a ginástica rítmica apresenta uma forma única de linguagem, que permite ao aluno descobrir, explorar e recodificar seus movimentos, além de experimentar novas possibilidades corporais e artísticas (BOAVENTURA, 2014).

Também, Ferreira Junior et al. (2012) afirmaram que a ginástica artística é uma ferramenta efetiva para o desenvolvimento psicomotor e pode facilitar a aquisição de habilidades e qualidades físicas, mostrando ao aluno como controlar seu próprio corpo em diversas situações. 
Perfil dos ingressantes na licenciatura em educação física e suas experiências...

Bruna Sontag • Verónica Gabriela Silva Piovani • Jorge Both • leda Parra Barbosa-Rinaldi

Outro aspecto, que se relaciona com a escassa vivência da ginástica de competição dentro da escola, é a predominância do ensino dos esportes dentro da EF escolar. Neste caso, a EF, que não é (nem deve ser) limitada aos esportes, acaba deixando de lado outros conteúdos também importantes, como as lutas, os jogos e brincadeiras, as danças e a ginástica (COSTA, et al., 2016).

Dentre os motivos apontados para a ausência da ginástica no conteúdo na EF escolar, destacam-se: a falta de preparação adequada dos professores, a falta de experiência, a falta de professores especialistas ministrando a disciplina no curso de graduação, a insegurança dos educadores em aplicar o conteúdo gímnico por considerarem-no perigoso e/ou a falta de materiais e equipamentos adequados (SCHIAVON; NISTA-PICCOLO, 2007; BARBOSARINALDI; PAOLIELLO, 2008; PORTO, 2014; COSTA, et al., 2016; CARRIDE et al., 2017; MARIANO et al., 2019).

Ao evidenciar que os estudantes que avaliaram de uma forma um pouco mais positiva a abordagem metodológica do conteúdo ginástica de competição nas aulas de EF foram aqueles com ocupação remunerada e que tiveram o conteúdo ginástica de competição na EF, pode-se inferir que as experiências pessoais relacionadas à socialização antecipatória podem incidir nesse julgamento. Isto porque os alunos que possuem experiência de trabalho, seja em qualquer área, possuem também uma criticidade diferente dos que não trabalham, tendo em vista que já estiveram no papel de ser julgado/avaliado.

Além disso, o fato de ter tido contato com a modalidade leva esses alunos a terem uma visão mais ampliada do conteúdo, suas dificuldades e suas possibilidades. Pois, se for trabalhada de maneira eficaz na vida escolar, a ginástica integra a formação educacional da criança, facilita e enriquece a fase acadêmica, proporcionando uma prática profissional futura de qualidade (BARBOSA-RINALDI; SOUZA, 2003; SCHIAVON; NISTA-PICCOLO, 2007).

Sendo assim, a identidade profissional desses alunos é construída de maneira gradativa, no decorrer da vida, antes da gradua- 
Perfil dos ingressantes na licenciatura em educação física e suas experiências... Bruna Sontag • Verónica Gabriela Silva Piovani • Jorge Both • leda Parra Barbosa-Rinaldi

ção, antes mesmo da carreira profissional. Em suma, é o processo chamado de socialização antecipatória, em que valores, normas, conhecimentos são interiorizados por meio de experiências pessoais, do contato com outros profissionais, família, amigos etc., e que interfere na forma de aprendizado, mas, também, na forma como esse aprendizado é transmitido (GOMES; QUEIRÓS; BATISTA, 2014).

Desta forma, verifica-se que o processo de socialização profissional na docência acontece durante toda a vida e não somente a partir do momento em que os estudantes ingressam na universidade e/ou começam a trabalhar como professores (LAWSON, 1983; GOMES; QUEIRÓS, BATISTA, 2014; ONOFRE; MARTINS, 2014). Assim, a socialização que começa desde a infância e, principalmente, as experiências com a carreira desejada, que acontecem antes de as pessoas entrarem na graduação, devem ser observadas (TEMPLIN et al., 2017).

A respeito da presença da ginástica de competição fora da EF escolar, evidenciou-se que a maioria desses alunos pertencia à $U 4$, era do sexo feminino, pertencia a escolas privadas e teve ginástica competitiva dentro da EF escolar.

Nesse ponto, Carbinatto et al. (2010) descreveram que atividades extracurriculares, como a ginástica, vêm crescendo de maneira progressiva devido a questões como o desejo de manter crianças e adolescentes ativos e inseridos em um ambiente enriquecedor. Além disso, o mesmo estudo apresenta que entre os principais motivos que levaram os estudantes a optarem pela prática de ginástica artística (ginástica de competição) estão: a influência da mídia, a família e o professor (motivos extrínsecos). E, em segundo lugar, o prazer pela prática e a autossuperação (motivos intrínsecos).

No presente estudo, evidencia-se que o contexto socioeconômico e cultural, no qual está localizada a U4, pode ter influenciado na hora de oferecer mais possibilidades de acesso a atividades esportivas para a população fora do ambiente escolar. Ressaltase que a U4 se encontra na cidade com menor população e que 
Perfil dos ingressantes na licenciatura em educação física e suas experiências... Bruna Sontag • Verónica Gabriela Silva Piovani • Jorge Both • leda Parra Barbosa-Rinaldi

possui um Índice de Desenvolvimento Humano² considerado alto $(0,774)$ (ATLAS DO DESENVOLVIMENTO HUMANO, 2010).

Neste sentido, Kytta (2002) descreve que cidades menores oferecem às crianças um ambiente mais natural e seguro para se deslocarem de maneira independente, sem a supervisão constante de adultos. Assim, essas cidades com menor porte, mais naturais, mais espaçosas e com espaços físicos mais seguros, podem facilitar outros tipos de comportamentos entre crianças e jovens, que não são tão comuns de serem observados em cidades maiores, como brincadeiras e jogos ao ar livre, além de facilitar o deslocamento para atividades físicas extraclasse.

Côte (2013), ao analisar características de atletas de alto nível no esporte de rendimento nos Estados Unidos e Canadá, descreve que a natureza íntima de cidades menores pode oferecer abordagens integrativas para a participação no esporte, pois envolvem as famílias, escolas e comunidade. Além disso, afirma que o contexto dessas cidades menores pode oferecer relações de apoio maior entre atletas e treinadores, promovendo efetivamente a abundância de normas sociais positivas.

Sobre o sexo dos alunos que vivenciaram a ginástica de competição fora da escola, observou-se que a maior parte era do sexo feminino (25\%). Este resultado remete às discussões de gênero, que são construções sociais e culturais que vêm sendo ressignificadas nos últimos anos. Goellner (2010) apresenta uma reflexão importante a respeito do gênero no esporte. Primeiramente, ela aponta que o gênero é uma condição social que diferencia o masculino do feminino. Portanto, é construído socialmente e, é a partir daí, que os corpos são significados a ações características do feminino ou do masculino. Ou seja, existem representações do que é feminino e do que é masculino, que por ser uma construção social, não são naturais, incidindo em mudanças e ressignificações no decorrer dos anos.

20 Índice de Desenvolvimento Humano está composto pelos Índices de Desenvolvimento Humano da Educação, de Longevidade e de Renda (ATLAS DO DESENVOLVIMENTO HUMANO, 2010). 
Perfil dos ingressantes na licenciatura em educação física e suas experiências...

Bruna Sontag • Verónica Gabriela Silva Piovani • Jorge Both • leda Parra Barbosa-Rinaldi

Rotular atividades como femininas ou masculinas, heterossexuais ou homossexuais, ocasiona em exclusões, inclusive no esporte. A anatomia dos corpos e as diferenças biológicas não justificam por si só a adesão (ou exclusão) a práticas esportivas (como no caso da ginástica). São as construções sociais do que é feminino e masculino que o fazem com maior ênfase.

$\mathrm{Na}$ EF escolar no Brasil, as questões de gênero são muito presentes, já que, em seu início, as aulas de EF eram separadas por sexo, com propostas diferenciadas, pois os homens necessitavam de um corpo forte para servir ao exército, e as mulheres precisavam se manter femininas e saudáveis para cumprir com sua função como reprodutoras de filhos (GALLARDO; BÁSSOLI; ARAVENA, 1998).

Por outro lado, é importante lembrar que essas diferenças e dificuldades da prática da ginástica de competição pelo gênero masculino estão também presentes na construção das próprias modalidades de ginásticas competitivas. Elas possuem regras oficiais ditadas pela Federação Internacional de Ginástica (FIG), que no caso da ginástica rítmica, ainda é exclusivamente reservada para o sexo feminino (GAIO; SANTOS, 2010).

Assim, no caso das diferenças de gênero na prática das modalidades gímnicas, é possível observar que a socialização antecipatória exerce um papel importante nos resultados evidenciados, já que os estudantes investigados, enquanto alunos da EF escolar, por sua própria experiência cultural e social, incorporam a ideia de atividades femininas separadas de atividades masculinas. $\mathrm{Na}$ etapa de socialização antecipatória, conforme Lawson (1983), os futuros profissionais da área incorporam conhecimentos, habilidades e valores que serão replicados na sua vida profissional. E, neste caso, estudos apontam que, em grande medida, os valores construídos durante a socialização antecipatória, não sofrem alteração no percurso da graduação (etapa de socialização profissional) (ONOFRE; MARTINS, 2014). 
Perfil dos ingressantes na licenciatura em educação física e suas experiências... Bruna Sontag • Verónica Gabriela Silva Piovani • Jorge Both • leda Parra Barbosa-Rinaldi

Percebe-se que houve uma relação significativa ao analisar o tipo de colégio no qual os estudantes cursaram o Ensino Médio e a experiência de ginástica de competição no ambiente extracurricular. Uma parte expressiva dos alunos de colégios privados vivenciou a modalidade fora da escola em comparação aos alunos de colégios públicos.

A respeito disso, ressalta-se que, em grande parte das escolas públicas, os materiais para a prática de EF de maneira ampla são precários e não existem locais apropriados à prática de atividade física, problemas que são causados por dificuldades em obter recursos financeiros. Embora a escola pública seja a maior rede do país e, consequentemente, possua um número muito maior de alunos do que a escola privada, a rede privada conta com uma meIhor estrutura física, melhores recursos, além de uma forte contribuição com projetos extracurriculares. Fatos que levam a aulas melhor ambientadas, com materiais e locais adequados (CELI e PANDA, 2012). No entanto, é importante destacar que Maldonado, Soares e Schiavon (2019) relatam, no seu trabalho com turmas de EF do Ensino Médio público em São Paulo, que a falta de materiais para desenvolver o conteúdo gímnico nas escolas pode ser solucionada com a criação de materiais alternativos.

Como pode se observar, os resultados deste estudo demonstram que, no processo de socialização profissional, as experiências prévias relacionadas ao conteúdo de ginástica de competição são muito importantes. Pois, em certo contexto sociocultural especial, a participação social induz o desenvolvimento de competências e valores específicos (ABRANTES, 2011). Desta forma, um futuro profissional de EF, que teve o conteúdo gímnico de maneira adequada durante o seu percurso escolar, teria maiores possibilidades de se interessar pelo conteúdo e de construir novas aprendizagens relacionadas ao ensino deste durante sua formação inicial em EF. 
Perfil dos ingressantes na licenciatura em educação física e suas experiências... Bruna Sontag • Verónica Gabriela Silva Piovani • Jorge Both • leda Parra Barbosa-Rinaldi

\section{Considerações finais}

As evidências encontradas a respeito do perfil de estudantes ingressantes no curso de Licenciatura em Educação Física de universidades públicas do Paraná, frente às atividades de ginástica de competição desenvolvidas durante sua educação básica, apontam que o percentual de alunos que vivenciaram a ginástica como conteúdo da EF escolar é escasso. Apesar das modalidades de ginástica olímpica e rítmica ser um conteúdo incluído nos PCN da Educação Física (BRASIL, 1997) e as ginásticas competitivas serem incluídas mais recentemente na unidade temática esporte na BNCC (BRASIL, 2017), é evidente que a grande maioria dos alunos ingressantes nos cursos de EF tem o primeiro contato com a ginástica de competição na própria graduação, fator que dificulta o aprendizado durante o curso e sua futura atuação neste campo profissional.

Ainda, percebe-se que a maior parte dos alunos que vivenciou a ginástica de competição fora da escola pertencia à $U 4$, o que pode estar relacionado às diferenças no contexto socioeconômico no qual se localizam essas universidades. Além disso, a maioria dos alunos era do sexo feminino, estudou em escolar privadas e vivenciou a ginástica de competição dentro da escola.

O conhecimento das experiências dos estudantes ingressantes no curso de EF Licenciatura, em relação ao conteúdo ginástica de competição, é importante, já que faz parte da socialização antecipatória dos futuros docentes e influencia a identidade profissional que eles vão desenvolver ao longo da carreira. Ao ter esse conhecimento, o currículo da formação inicial pode ser organizado de modo que as experiências de formação inicial proporcionem um contato direto e contextualizado com a realidade de um processo de ensino de qualidade. Ou seja, as experiências prévias dos estudantes com a aprendizagem desse conteúdo, poderiam servir de ponto de partida para discutir as possibilidades de planejamento e organização das atividades em dois âmbitos: a prática como 
Perfil dos ingressantes na licenciatura em educação física e suas experiências...

componente curricular ou como proposta de extensão universitária. Principalmente, para poder alterar as crenças que os estudantes trazem consigo ao entrar na universidade. Neste caso, pode-se começar a organizar o curso de graduação atendendo às particularidades da situação de carência do conteúdo no histórico escolar dos estudantes. E talvez, no futuro, poder reverter este quadro na EF escolar.

Destaca-se que o presente estudo somente utilizou um questionário com questões abertas e fechadas para a coleta de dados, o que acaba limitando a possibilidade de aprofundamento de informações relacionadas às vivências dos estudantes. Nesse caso, sugere-se a realização de novos estudos que usem instrumentos que possam oferecer informações mais detalhadas das experiências dos estudantes com a ginástica de competição na Educação Física escolar.

\section{Referências}

ABRANTES, P. Para uma teoria da socialização. Revista da Faculdade de Letras da Universidade do Porto, v. 11, p. 121139, 2011.

ANDRADE, T. V. C. de; ROCHA, E. C. SILVA; ALVES, M. P; FONSECA, M. C. V. Ligações entre o ensino de ginástica artística escolar e o desenvolvimento motor de crianças: um estudo de revisão.

Revista Práxia, v. 8, n. 16, 2016.

ATLAS DO DESENVOLVIMENTO HUMANO - [Sítio Web]. Índice de Desenvolvimento Humano Municipal (IDHM) e outros 200 indicadores de demografia, educação, renda, trabalho, habitação e vulnerabilidade para os municípios brasileiros, 2010. Disponível em: http://atlasbrasil.org.br/2013/. Acesso em: 05 dez. 2019.

AYOUB, E. Ginástica geral e educação física escolar. 2. ed. Campinas, SP: Editora da Unicamp, 2007. 
Perfil dos ingressantes na licenciatura em educação física e suas experiências...

Bruna Sontag • Verónica Gabriela Silva Piovani • Jorge Both • leda Parra Barbosa-Rinaldi

BARBOSA-RINALDI, I. P. B.; PAOLIELLO, E. Saberes ginásticos necessários à formação profissional em educação física: encaminhamentos para uma estruturação curricular. Rev. Bras. Cienc. Esporte, Campinas, v. 29, n. 2, p. 227-243, 2008.

BARBOSA-RINALDI, I. P. B.; SOUZA, E. P. M. de. A ginástica no percurso escolar dos ingressantes dos cursos de licenciatura em educação física da universidade estadual de Maringá e da universidade estadual de campinas. Rev. Bras. Cienc. Esporte, Campinas, v. 24, n. 3, p. 159-173, 2003.

BARROS, I. M. C. Contributo para a compreensão do processo de (re)construção da identidade professional no contexto da formação inicial: estudo em estudantes estagiários de Educação Física. 2011. Dissertação - Universidade do Porto, Porto, 2011. BOAVENTURA, P. L. B. Ginástica rítmica em esporte-conteúdo nas aulas de educação física escolar. Cadernos de Formação RBCE, p. 45-55, 2014.

BRASIL. Secretaria de Educação Fundamental. Parâmetros Curriculares Nacionais: Educação Física. Brasília: MEC/SEF, 1997. Disponível em: http://portal.mec.gov.br/seb/arquivos/pdf/livro07. pdf. Acesso em: 05 dez. 2019.

BRASIL. Ministério da Educação. Base Nacional Comum Curricular. Educação Física. Brasília: MEC, 2017. Disponível em: http://basenacionalcomum.mec.gov.br/images/BNCC_El_ EF_110518_versaofinal_site.pdf. Acesso em: 05 dez. 2019.

CARBINATTO, M. V.; et al. Motivação e ginástica artística no contexto extracurricular. Conexões, v. 8, n. 3, p. 124-145, set./dez. 2010.

CARRIDE, C. A.; et al. O ensino da ginástica de Itatiba/SP: de volta as escolas. Motrivivência, v. 29, n. 51, p. 83-99, 2017.

CERVO, A. L.; BERVIAN, P. A. Metodologia Científica: para uso dos estudantes universitários. 4. ed. São Paulo: Makron Books, 1996. 
Perfil dos ingressantes na licenciatura em educação física e suas experiências... Bruna Sontag • Verónica Gabriela Silva Piovani • Jorge Both • leda Parra Barbosa-Rinaldi

CELI, J. A.; PANDA, M. D. J. A Educação Física nas escolas públicas e privadas. Em: COSTA, A. A. C. et al. (Orgs.) Anais [recurso eletrônico] do XVII Seminário Interinstitucional de Ensino, Pesquisa e Extensão; XV Mostra de Iniciação Científica e X Mostra de Extensão, “Ciência, Reflexividade e (In)Certezas", 06 a 08 de outubro de 2012.Cruz Alta, RS: Unicruz, Centro Gráfico, 2012. Disponível em: https://home.unicruz.edu.br/seminario/anais/ anais-2012/ccs/a\%20educacao\%20fisica\%20nas\%20escolas\%20 publicas\%20e\%20privadas.pdf. Acesso em: 05 dez. 2019.

COSTA, A. R. et al. Ginástica na escola: por onde ela anda professor? Conexões, Campinas, v. 14, n. 4, p. 76-96, 2016.

CÔTÉ, J. Pathways to expertise in team sport. Em: NASCIMENTO, J. V. do; RAMOS, V.; TAVARES, F. (Orgs.). Jogos desportivos: formação e investigação. Florianópolis: UDESC, 2013. p. 59-77.

GAIO, R. C.; SANTOS, A. P. dos. Ginástica e discussão de gênero: a ginástica rítmica na formação profissional em educação Física. ANAIS [recursos eletrônicos] do Fazendo Gênero 9 - Diásporas, Diversidades, Deslocamentos, de 23 a 26 de agosto de 2010. Florianópolis, SC: UFSC. Disponível em: http://www.fazendogenero.ufsc.br/9/resources/anais/1275507427_ARQUIVO_ Ginasticaediscussoesdegenero2010.pdf. Acesso em: 05 dez. 2019. GALLARDO, J.S.P; BÁSSOLI, A.A de O; ARAVENA, C.J.O. Didática de Educação Física: a criança em movimento: jogo, prazer e transformação. São Paulo: FTD, 1998.

GÖELLNER, S. V.A educação dos corpos, dos gêneros e das sexualidades e o reconhecimento da diversidade. Cadernos de Formação RBCE, p. 71-83, mar. 2010.

GOMES, P.; QUEIRÓS, P.; BATISTA, P. A socialização antecipatória para a profissão docente. Sociologia, Revista da Faculdade de Letras da Universidade do Porto, v. XXVIII, p. 167-192, 2014. GRAÇA, A. A construção da identidade profissional em tempos de incerteza. In: BATISTA, P.; GRAÇA, A.; QUEIRÓS, P. O estágio profissional da (re) construção da identidade profissional em educação física, Porto: Ed. U.PORTO, 2014. 
Perfil dos ingressantes na licenciatura em educação física e suas experiências... Bruna Sontag • Verónica Gabriela Silva Piovani • Jorge Both • leda Parra Barbosa-Rinaldi

FERREIRA JUNIOR, C.; ALVARENGA, J. P. P.; VIANA, M. A. S.; ARÊAS NETO, N. T. A ginástica artística como conteúdo da educação física escolar. Perspectivas online, v. 5, n. 2, p. 12-22, 2012. KYTTA, M. Affordances of children's environment'sin the context of cities, small towns, suburbs, and rural villages in Finland and Belarus. Journal of Environmental Psychology, v. 22, p. 109123, 2002.

LAWSON, H. A. Toward a model of a teacher socialization in physical education: the subjective warrant, recruitment, and teacher education. Journal of Teaching in Physical Education, 2, 3, p. 3-16, 1983.

MALDONADO, D. T.; SOARES, D. B.; SCHIAVON, L. M. Educação Física no ensino médio: reflexões e desafios sobre a tematização da ginástica. Motrivivência, v. 31, n. 60, p. 01-19, 2019.

MARIANO, M. L.; PARENTE, M. L. da C.; XAVIER JUNIOR, J. F.; MOURA, D. L. O ensino da ginástica da Educação Física: uma revisão sistemática. Motrivivência, v. 31, n. 60, p. 01-17, 2019. MERIDA, F.; NISTA-PICCOLO, V. L.; MERIDA, M. Redescobrindo a ginástica acrobática. Movimento. Porto Alegre, v. 14, n. 02, p. 155-180, 2008.

NISTA-PICCOLO, V. L. Atividades físicas como proposta educacional para $1^{\text {a }}$. Fase do $\mathbf{1}^{\circ}$. Grau. Campinas, 1988, Dissertação (Mestrado em Educação Física). Faculdade de Educação, Universidade Estadual de Campinas, Campinas, SP, 1988.

OLIVEIRA, G. M.; PORPINO, K. de O. Ginástica Rítmica e educação física escolar: perspectivas críticas em discussão. Pensar a prática, Goiânia, v. 13, n. 2, p. 1-18, 2010.

ONOFRE, M.; CARVALHO, L. M. Sources of teacher's pedagogical knowledge: An interpretative analysis from reports in significant experiences of occupational socialization. Em: KLISSOURAS, V.; KELLIS, S.; MOURATIDIS, I. (Eds.). Sport Sciences through the ages - Challenges in the new millennium. Thessaloniki, Grécia: 
Perfil dos ingressantes na licenciatura em educação física e suas experiências...

Bruna Sontag • Verónica Gabriela Silva Piovani • Jorge Both • leda Parra Barbosa-Rinaldi

Proceedings of the 2004 Pre-Olympic Congress, Thessaloniki, Grécia, 2004.

ONOFRE, M.; MARTINS, M. J. Elementos para a qualificação das práticas de supervisão pedagógica nos estágios pedagógicos. In: BATISTA, P.; GRAÇA, A.; QUEIRÓS, P. O estágio profissional na (re)construção da identidade profissional em Educação Física. Porto: FADEUP, 2014. p. 297 - 310.

PORTO, J. A ginástica na educação física escolar de estudantes universitários da Universidade Estadual Paulista/Campus de Rio Claro. 2014. 54 f. Trabalho de conclusão de curso (licenciatura - Educação Física). Universidade Estadual Paulista, Instituto de Biociências de Rio Claro, 2014. Disponível em: http://hdl.handle. net/11449/131754. Acesso em: 05 dez. 2019.

SANTOS, S. dos; GHELLER, R. G. Construção e validação de instrumentos para coleta. In: SANTOS, S. dos; MORETTI-PIRES, R. O. (Orgs.). Métodos e Técnicas de Pesquisa Qualitativa aplicada à Educação Física. Florianópolis: Tribo da Ilha, 2012. p. 195 - 206. SCHIAVON, L; NISTA-PICCOLO, V. A ginástica vai à escola. Movimento, Porto Alegre, v. 13, n. 03, p. 131-150, 2007.

SOUZA, E. P. M. de. Ginástica geral: uma área do conhecimento da Educação Física. 163 f. [Tese] Doutorado. Faculdade de Educação Física, Universidade Estadual de Campinas, Campinas, 1997.

\section{Financiamento}

Esse trabalho contou com apoio e financiamento do Conselho Nacional de Desenvolvimento Científico e Tecnológico (CNPq) Programa Institucional de Bolsas de Iniciação Científica (PIBIC).

\section{Aprovação de comitê de ética em pesquisa}

pesquisa aprovada pelo Comitê de Ética da Universidade Estadual de Maringá. Título: Ginásticas competitivas no percurso 
Perfil dos ingressantes na licenciatura em educação física e suas experiências...

Bruna Sontag • Verónica Gabriela Silva Piovani • Jorge Both • leda Parra Barbosa-Rinaldi

escolar de ingressantes de cursos de Licenciatura em Educação Física no Paraná.

\section{Publisher}

Universidade Federal de Goiás. Faculdade de Educação Física e Dança. Publicação no Portal de Periódicos UFG. As ideias expressadas neste artigo são de responsabilidade de seus autores, não representando, necessariamente, a opinião dos editores ou da universidade. 